\title{
LA PERFORMANCE POÉTICA EN LA OBRA DE GUAQUIN, HUENUÑIR Y MANQUEPILLAN: UNA LECTURA CRÍTICA ${ }^{1}$
}

\author{
María Soledad Falabella Luco \\ Universidad de Chile \\ Santiago, Chile \\ sfalabella@uchile.cl
}

RESUMEN / ABSTRACT

En la última década, la esfera pública chilena se ha vitalizado con las múltiples voces de autoras mapuche. Este histórico proceso está profundamente influenciado por el carácter oral, colectivo y comunitario de su cultura, en la que conviven lo poético, lo político y lo espiritual. En el presente artículo llevo a cabo un análisis históricamente crítico de la poesía de Karla Guaquin, María Huenuñir y Faumelisa Manquepillan, todas coautoras de las antologías Hilando en la memoria (2006) e Hilando en la memoria. Epu Rupa (2009). Analizo críticamente cómo desde el lenguaje poético sus voces no solo enuncian un discurso, sino que crean un lugar propio en disputa con el espacio de silencio y de exclusión que tradicionalmente les ha otorgado el discurso hegemónico de la República de Chile. Mediante la poesía irrumpen en la esfera pública para poner en circulación nuevos lugares transformadores, que, como "tretas del débil", tejen estética, ética y políticamente una memoria comunitaria y resistente frente a la cultura patriótica chilena. Propongo que su poesía, a través la performatividad de su marcada

1 El presente ensayo es una traducción propia del inglés con edición actualizada, editada y sustancialmente aumentada, basada en el capítulo "Hilando en la Memoria: Weaving Songs of Resistance in Contemporary Mapuche Political Cultural Activism”, el cual publiqué en Women Mobilizing Memory, por Columbia University Press en 2019, pp. 459-478. Este libro, editado por Ayşe Gül Altýnay, María José Contreras, Marianne Hirsch, Jean Howard, Banu Karaca y Alisa Solomon, nace de del grupo de trabajo "Women Mobilizing Memory", grupo interdisciplinario de artistas, activistas y académicas feministas para dar voz a diversos testimonios de violencia de género y sus intersecciones, reparando en el estudio y las prácticas de la memoria que aquí hacen justicia mediante la reconfiguración de relatos silenciados y tergiversados en las narrativas de la dominación. 
oralidad, opera como un trawun (encuentro o asamblea), un escenario que posibilita la creación de nuevas agencias e imaginarios, tanto para el pueblo mapuche como para otros pueblos, incluido el chileno. Se trata de un ejercicio de creatividad, resistencia y transformación capaz de subvertir el discurso patriótico chileno que, durante los últimos doscientos años, ha buscado subyugar todo lo mapuche, su enemigo interno constitutivo, con el fin de apropiarse de su cultura como un insumo para la constitución de la República. Veremos cómo, en su quehacer poético, las autoras movilizan el horror traumático vivido por generaciones, tanto mapuche como chilenas (especialmente a partir de la dictadura cívico-militar), transformándolo en un ethos colectivo en torno al küme felen o mogen (estar bien o buen vivir).

Palabras clave: Hilando en la memoria, pueblo mapuche, escritura de mujeres, género, Chile.

\section{THE POETIC PERFORMANCE OF GUAQUIN, HUENUNIIR AND MANQUEPILLAN'S WORKS: A READING FROM THE STANDPOINT OF "THE TRICKS OF THE WEAK"}

In the last decade, the Chilean public sphere has been vitalized by the multiple voices of a chorus of Mapuche authors. This historical process is profoundly marked by the oral, collective, and communal character of their culture, a culture in which the poetic, the political and the spiritual coexist. In this essay I query through a historically critical analysis of the poetry of Karla Guaquin, Maria Huenuñir y Faumelisa Manquepillan, all of them co-authors in the Hilando en la memoria (2006) e Hilando en la memoria. Epu Rupa (2009) anthologies, how the emergence and entry of voices of Mapuche women impacts the Chilean public sphere. Specifically, I focus on how their poetry creates and circulates new knowledge, and functions like "tricks of the weak" enabling communities to weave their own inclusive, diverse, and collective memory, from an aesthetical, ethical, and political standpoint. I claim that their writings not only enunciate a new discursivity, but also, through the performance of their poetic writing, they create a place of resistance and contestation to the hegemonic discourse of the Republic of Chile, whose violence has sought to erase the Mapuche people and their culture. Indeed, their poetry performs the act of subverting the Chilean patriotic discourse that for the last 200 years has sought to erase everything Mapuche, its constitutive internal enemy. We will see how in their poetic language, full of orality and performativity, operates as a trawun (meeting or assembly), a stage that mobilizes the traumatic horror experienced by generations, both Mapuche and Chilean (especially since the civic-military dictatorship), transforming it into a collective ethos around küme felen / mogen (to be well / good living and in equilibrium with nature).

KEYWORDS: Hilando en la memoria, Mapuche, women's writing, gender, Chile. 


\section{INTRODUCCIÓN}

En la última década, la esfera pública chilena se ha vitalizado con las múltiples voces de autoras mapuche. Este histórico proceso está profundamente influenciado por el carácter oral, colectivo y comunitario de su cultura, en la que conviven lo poético, lo político y lo espiritual. Estas características implican la creación de una escritura cuyo lenguaje está cargado de fuerza actancial, esto es, una escritura cuya performance tiene el potencial de hacer cosas en el mundo. En el presente artículo llevo a cabo un análisis históricamente crítico de la performance en la escritura poética de Karla Guaquin, María Huenuñir y Faumelisa Manquepillan, todas coautoras de las antologías Hilando en la memoria (2006) e Hilando en la memoria. Eри Rupa (2009). Motivada por la crítica literaria feminista y los estudios del performance, en el presente ensayo investigo cómo estas autoras, junto a muchas otras, irrumpen en la esfera pública chilena para poner en circulación nuevos lenguajes, potencias e imaginarios, tejiendo estética, ética y políticamente una memoria comunitaria, incluyente y resistente al discurso patriarcal hegemónico de Chile.

En el ensayo "Las tretas del débil"2 (1985) -incluido en la antología $L a$ sartén por el mango del "Encuentro de Mujeres Latinoamericanas" (1982)-, Josefina Ludmer nos invita a entender la "Respuesta a Sor Filotea de la Cruz" (1691), de Sor Juana Inés de la Cruz, como un complejo dispositivo cuya escritura es capaz de actuar en el mundo, transformándolo no solo a nivel de la situación comunicacional inmediata, sino también a nivel de "las relaciones sociales y la producción de ideas y textos" $(47)^{3}$. Ludmer remarca

\footnotetext{
"Las tretas del débil", uno de los textos fundacionales de la teoría literaria feminista latinoamericana, se inscribe en el campo de los estudios de la voz autorial, los actos de habla, el discurso y el performance (J V. Woolf, J.L. Austin, J. Searle, M. Foucault, G. Rubin, D. Haraway, R. Lakoff, A. Dworkin, H. Arendt, N. Fraser, J. Derrida, J. Kristeva). Esta inscripción es especialmente importante para cuestionar la relación entre las voces de mujeres, el lugar de la enunciación, el cuerpo, la mirada y lo político. En esta misma tradición crítica en torno al poder actancial y transformador del lenguaje, especialmente vinculado a la reflexión sobre el aparecer en la polis de mujeres que se toman la palabra pública, está la obra feminista de Virginia Woolf, Julieta Kirkwood, Teresa de Lauretis, Judith Butler, Nelly Richard y Diana Taylor.
}

Esta carta de Sor Juana Inés de la Cruz fue escrita en México en 1691, pero recién fue publicada casi diez años después, en España, en 1700. En ella, Sor Juana le responde al obispo de Puebla, Manuel Fernández de Santa Cruz, que en la famosa se hace pasar por mujer, 
el lugar desde donde se enuncia la voz actancial y su efecto transformador en el mundo:

Hablaremos de lugares. Por un lado, un lugar común de la crítica: la Respuesta de Sor Juana Inés de la Cruz a Sor Filotea; por otro lado un lugar específico: el que ocupa una mujer en el campo del saber, en una situación histórica y discursiva precisa. [...] Respecto del lugar específico, se trata de otro tipo de discordancia: la relación entre este espacio que esta mujer se da y ocupa, frente al que le otorga la institución y la palabra del otro: nos movemos, también, en el campo de las relaciones sociales y la producción de ideas y textos. Leemos en esta carta ciertas tretas del débil en una posición de subordinación y marginalidad (47).

La autora de "Las tretas del débil" reflexiona sobre los "lugares" que se crean a partir de la obra. El primero es el lugar que ocupa ella misma como crítica, realizando una relectura de una obra clásica. Luego, está el lugar específico y propio que Sor Juana crea escribiendo la "Respuesta": "este espacio [discursivo] que esta mujer [Sor Juana] se da y ocupa" (ibid.). Con este gesto, la autora está proponiendo leer la "Respuesta" como un texto performativo, cuyo lenguaje es capaz, no solo de describir el mundo, sino también de realizar aquello que denota ${ }^{4}$.

travistiéndose como "Sor Filotea de la Cruz" y amenaza a Sor Juana con la inquisición por haber escrito y hecho pública la famosa "Carta Atenagórica" donde Sor Juana critica un sermón del padre Vieyra sobre las finesas de Cristo. El obispo de Puebla -el hombre más poderoso de México, se decía que incluso era más poderoso que el mismo rey- busca poner en su lugar a Sor Juana como mujer y monja. La acusa de violar las leyes fundamentales de la Iglesia al estudiar y no guardar silencio. "Sor Filotea" le recuerda a Sor Juana que, según la doctrina de la Iglesia, las mujeres debían guardar silencio y no debían estudiar, ni menos hacer públicas sus opiniones sobre temas filosóficos, menos aún teológicos. Ver: M.L. Femenías, J. Franco, O. Paz y Y. Martínez San Miguel. Asimismo, este tema está maravillosamente tratado en la película de la cineasta María Luisa Bemberg, Yo la peor de todas, de 1990.

En la obra Cómo hacer cosas con palabras (1962) de J. L. Austin, el autor llama actos perlocutivos los actos de habla que no solo se refieren al mundo, sino que también lo crean. Más tarde, J. Searle en su libro Actos de habla. Un ensayo sobre la filosofía del lenguaje (1969) ampliará el concepto de "performativo" afirmando que la performatividad es inherente a todo el lenguaje, no solo a ciertos actos de habla. A su vez, la crítica literaria y lingüista J. Kristeva se refiere a la capacidad de "hacer cosas" del lenguaje poético en Revolución del lenguaje poético (1974). Pero será la filósofa J. Butler quien extrapolará esta fuerza "actancial" o "realizativa" del lenguaje para afirmar que el género es un efecto 
El lugar que Sor Juana "se da y ocupa" se constituye en un escenario "histórico y discursivo específico", donde el espacio que se autogestiona y ocupa para constituirse se enfrenta al lugar que le otorga la institución y la palabra del otro. Así, Ludmer nombra y visibiliza la distancia asimétrica del lugar de Sor Juana y el lugar que le otorga el otro hegemónico. Es esta distancia asimétrica la que Sor Juana aprovecha y transforma en una oportunidad para sacar su voz y prevalecer. Josefina Ludmer llama a esto "las tretas del débil" (48).

La belleza de la lectura de Ludmer es que permite visibilizar y valorar el poder de agencia (enunciación de la voz propia, creación de un nuevo lugar propio y específico y la resistencia creativa frente a la norma hegemónica) de Sor Juana al alzar su voz y tomarse el espacio para resistir ante la sanción y amenaza de muerte de los tribunales de la Inquisición.

Siguiendo la lectura crítica de Josefina Ludmer, propongo leer la escritura poética de Karla Guaquin, María Huenuñir y Faumelisa Manquepillan para reflexionar sobre el lugar específico que ellas se dan y ocupan en sus obras tanto a nivel discursivo, como también social y político. Las autoras podrían estar, tal como Sor Juana, en una posición asimétrica frente al discurso del otro, que, en el caso de Chile, es el discurso patriótico republicano. Pienso que una lectura como esta es particularmente necesaria a la hora de pensar los procesos de legitimación de la cultura oral y escritural mapuche, que hoy están en un punto de inflexión después de la revuelta social y el proceso constituyente que estamos viviendo. En ambos, el pueblo mapuche, su lucha y cultura han estado en primera línea ${ }^{5}$.

performativo del discurso: "performativity must be understood not as a singular or deliberate 'act', but, rather, as the reiterative and citational practice by which discourse produces the effects that it names" (2).

La bandera mapuche pasó a ser el símbolo más emblemático de la revuelta social, emblema que se cristaliza en la famosa foto, del día 25 de octubre de 2019, de la estatua de Baquedano de Plaza Dignidad tomada por manifestantes con banderas, siendo la mapuche la más alta, y el foco de la mirada. Comenta la periodista Marcia Carmo de la $B B C$ : "Sobre la multitud se alza un joven descamisado que acaba de conquistar la estatua de un héroe militar. Hay humo. Ondea la bandera mapuche... es la foto más icónica de las protestas en Chile (párr. 1)". El año siguiente, 2020, el Premio Nacional de Literatura fue otorgado al poeta Elicura Chihuailaf Nahuelpan "por su vasta trayectoria y su capacidad de instalar la tradición oral de su pueblo en una escritura poderosa que trasciende a la cultura mapuche (Prieto párr. 1)". Junto con esto, la elección de la doctora Elisa Loncon Antileo como presidenta de la Convención Constitucional no solo ha visibilizado la riqueza de su cultura y su gente, 
Es más, en las antologías las poetas se refieren al lugar que están construyendo con sus escritos. Entienden su escritura como un ejercicio de poder creativo de voces, redes y memoria. Roxana Miranda Rupailaf, editora del segundo volumen de Hilando en la memoria, describe este lugar como un espacio propio donde las distintas voces crean un tejido nuevo y plural en diálogo con la sociedad y abierto hacia el futuro:

Hilando en la memoria es un esfuerzo por registrar las aclamadas voces de la poesía de las mujeres mapuche, así como las más nuevas y contemporáneas. [...] Tanto esta antología como la anterior son el tejido de una obra mayor que aún espera futuros hilos y colores por descubrir [...]. [Esta experiencia] se ha enriquecido con esta minga de la hiladura de palabras, en la que hemos participado para crear una tonalidad, un caleidoscopio de escritoras de memoria, críticos literarios, profesores, editores, coordinadores y todos los demás colaboradores (Falabella, Huinao y Miranda 9).

Estas palabras de la poeta Roxana Miranda Rupailaf dan cuenta de la profundidad del entendimiento de las autoras, no solo en términos de diversidad y colectividad, sino también para distintas generaciones y tiempos indeterminados, en tanto ocupan y crean un espacio intergeneracional y colectivo de memoria. La escritura poética del libro se entiende como un sistema complejo, portador de una posibilidad de "aparecer" e intervenir en "una obra mayor que aún espera futuros hilos y colores por descubrir". Esto es, participar como "escritoras de memoria" en un espacio colectivo, abierto no solo hacia el futuro, sino también hacia el pasado. La performance de la oralidad en la poesía escrita, habilita a las autoras y sus comunidades a trabajar con la memoria como espacio creativo y de transformación, ejercicio que, según Elizabeth Jelin, posibilita un escenario donde "pensar y analizar las presencias y sentidos del pasado" (2).

Para entender cómo opera la performance de la oralidad, cabe recordar la obra El cantor de cuentos (1960), de Albert Lord, sobre los cantores tradicionales de los Balcanes, donde el autor plantea que, al traspasar los

sino también ha demostrado su potencia y aporte al asumir un cargo de poder en la sociedad chilena. En efecto, la poeta Faumelisa Manquepillán Calfuleo fue candidata a Senadora por la Región de los Ríos, con 3,730 votos, la cuarta mayoría de su pacto. Hace diez años, esto era impensable. 
cantos de la tradición oral a la escritura, se produce un exceso que sobrepasa la página escrita. Esto es, el texto escrito es portador de un exceso que lo sobrepasa y a esto Lord le llama performance. En esta misma línea, desde los estudios medievales, Paul Zumthor, en su artículo fundacional "L'intertexte performanciel" (1984), concibe la performance como la cualidad subversiva de la norma letrada que identifica a los textos que se crean en el contexto sociocultural de la oralidad. La oralidad en estos textos opera como un intertexto capaz de subvertir la escritura-lo que recuerda el título paradójico del ensayo del lingüista Wulf Österreicher: "Lo hablado en lo escrito" (1996)-.

Por otra parte, Diana Taylor plantea que el término "performance" es muy problemático, ya que se refiere a un amplio rango de acontecimientos. Subraya que la performance es un fenómeno que va más allá de lo meramente discusivo, esto es un acto corporeizado (embodied) que ocurre en el mundo. En una entrevista de 2002, la autora destaca el aspecto múltiple y abierto de los estudios del performance cuando especifica que más que limitarse a estudiar el discurso, estos toman en cuenta todo el "sistema performático" (Taylor párr. 4) que entra en juego, ampliando la forma en que se piensa la creación y transmisión de conocimientos más allá de lo puramente lingüístico. El enfoque de Taylor permite romper con estructuras epistemológicas fragmentadas según disciplinas, liberando los modos de conocer, crear y comunicar fuera de las restricciones tradicionales de la academia.

En el presente ensayo utilizo el término "performance" según lo planteado por Lord y Zumthor en relación con la oralidad como un exceso que ocurre en los textos escritos, un exceso que tiene el potencial de subvertir la norma letrada. También, tomo la multiplicidad y amplitud del enfoque de Taylor, que permite ir más allá de lo meramente lingüístico, habilitando otros modos de conocer, crear y comunicar el conocimiento. Teniendo esto en mente, me quedan las siguientes interrogantes: ¿cómo opera la oralidad en la escritura poética de Faumelisa Manquepillan, Karla Guaquin y María Huenuñir? ¿Qué efecto tiene en sus lectores y contexto? ¿En qué consisten sus tretas del débil? ¿Qué lugares se crean y ocupan? ¿Cuáles son los nuevos lenguajes e imaginarios con los que desatan sus poemas? ¿Cómo se relaciona esta poesía con el discurso nacional del "ser chileno" y del "ser mapuche”? ¿Hay puntos de encuentro en la poesía para ambas audiencias? 


\section{POESÍA E IDENTIDAD NACIONAL}

Históricamente, la poesía ha sido un medio poderoso para la expresión de las luchas de identidad nacional en Chile y Abya Yala ${ }^{6}$. En efecto, el lenguaje poético tiene el potencial de generar nuevos discursos capaces de dotar de nombre a realidades previamente ininteligibles ${ }^{7}$. Cuando en 2001 comenzamos a diseñar el proyecto "Encuentro con Mujeres Mapuche" no circulaban libros de autoras mapuche, no así en el caso de los autores varones. Al indagar, encontramos uno o dos libros que no estaban en circulación en el país. Algo pasaba que las voces de autoras mapuche aún no gozaban de la necesaria legitimidad para ello. Las antologías Hilando en la memoria (2006) e Hilando en la memoria. Epu Rupa (2009) son el resultado de ese proyecto.

En los años siguientes, comenzaron a aparecer más y más voces de mujeres mapuche en los circuitos nacionales e internacionales en ámbitos académicos y culturales. Hoy en día, una década después, no solo han publicado tanto en Chile como en el extranjero, sino que han sido traducidas y recibido importantes distinciones no solo literarias sino también políticas: Elisa Loncon preside la Convención Constitucional y Faumelisa Manquepillan es candidata al Senado por la Región de los Ríos. Esta transformación social ha impactado en la vida de las autoras, las que han podido transformarse en mujeres trabajadoras de la cultura y la educación, poetas, escritoras académicas y activistas político-culturales ${ }^{8}$.

6 El nombre Abya Yala refiere a los territorios de todo el continente americano. Se trata de un concepto político cuyo uso fue propuesto por Constantino Lima en la Segunda Asamblea General de la Consejo Mundial de los Pueblos Indígenas, en Kiruna, Samilandia, Suecia, en 1977 (Portugal y Macusaya 211-271).

El poder de movilización del poeta luchador por la libertad es captado magistralmente por el héroe nacional de Cuba, José Martí, poeta y fundador del Partido Revolucionario Cubano. La poesía, en tanto lucha por una nueva forma de vida liberada de la dominación, se puede rastrear en La Araucana de Alonso de Ercilla (1569), Hojas de hierba de Walt Whitman (1855), Versos Sencillos de José Martí (1891), Cantos de vida y Esperanza de Rubén Darío (1905), Canto General de Pablo Neruda (1950), Montaje de un sueño diferido de Langston Hughes (1951), Aullido de Allen Ginsberg (1954), Poema de Chile de Mistral (1967), Sé por qué canta el pájaro enjaulado de Maya Angelou (1969), La bandera de Chile de Elvira Hernández (1991) y en Citizen: An American Lyric de Claudia Rankine (2014), entre otros.

Vale mencionar también que Emilia Nuyado Ancapichún es diputada de la República y que existe la Asociación de Municipalidades con Alcaldes Mapuche (AMCAM) desde 2014. Asimismo, Elicura Chihuailaf obtuvo el Premio Nacional de Literatura el año 2020 y 
Las claras y poéticas palabras de María Teresa Panchillo ${ }^{9}$, una de las zomo weycafe (mujeres guerreras) de Hilando en la memoria, expresan cómo el discurso poético no solo puede ser político, sino también transformador:

\begin{abstract}
¿Por qué escribo? Al ver la realidad terrible de la dictadura me hizo escribir; cualquiera podía caer muerto en un día de protesta. Ese miedo que provocan las dictaduras al no poder decir lo que sientes. Mis primeros versos fueron de denuncia y resistencia. En ese tiempo no se veía un futuro para nadie, menos para los pueblos originarios. [...] En la poesía me he abierto un espacio y ha sido mucho más dificil que a los hombres, pero con mis pares mapuche me llevo muy bien y veo hacia adelante que la poesía también es un arma en la lucha, y sirve para educar, sirve para que conozcan nuestro idioma, y como dijo un poeta catalán (Gabriel Celaya) "LA POESÍA ES UN ARMA CARGADA DE FUTURO” (Huinao et al. 149-150).
\end{abstract}

Vemos cómo Panchillo se abre camino en la poesía, donde, a pesar de las dificultades adicionales que debió enfrentar por ser mujer, forjó un nuevo futuro, tanto para sí como para su comunidad. La poesía ha actuado como un dispositivo cuyos efectos transformadores culturales, sociales y políticos estamos presenciando hoy en Chile ${ }^{10}$.

la doctora y profesora universitaria Elisa Loncon fue elegida presidenta de la Convención Constitucional en el presente año (2021).

9 María Teresa Panchillo nació en la comunidad de Küyumko, a las orillas del río Bio-Bio.

10 No quiero pasar por alto que muchas de las mujeres mapuche de la primera antología no habían terminado su educación primaria y habían viajado a Santiago desde el sur de Chile a una edad muy joven -a veces 11 o 12 años- para emplearse como nanas (trabajadoras domésticas), un trabajo de estatus social que se ha comparado con el de esclavos. Un ejemplo prodigioso de cómo estas mujeres creativas han podido transformar y cambiar su posición en la sociedad chilena es el de Graciela Huinao, coeditora de las antologías Hilando en la memoria (2006) e Hilando en la memoria. Epu Rupa. (2009). En 2014, en reconocimiento a su contribución al lenguaje, Huinao fue introducida en la Academia Chilena de la Lengua y ha viajado dos veces con la presidenta Michelle Bachelet. Entrar en la Academia de la Lengua y viajar con la Presidenta de Chile es una de las principales formas en que los escritores son reconocidos por la sociedad chilena en su conjunto. El último honor también ha sido asignado a Faumelisa Manquepillan, quien viajó con Bachelet a Estados Unidos en 2008 y se ha convertido en una fuerte líder espiritual, cultural y social en su comunidad natal de Puquiñe. Otro ejemplo destacable es el de Roxana Miranda Rupailaf, coeditora de la segunda antología, quien ha ganado numerosos premios nacionales e internacionales, entre ellos la 
La poesía de Karla Guaquin, publicada en el segundo volumen de Hilando en la memoria, también toma la voz de la zomo weycafe (mujer guerrera). Sin embargo, lo hace desde una forma muy distinta. En "Deshidratándole la Vida", una voz exclama:

\author{
"Deshidratándole la Vida" \\ Ya no corre \\ más agua por estas tierras \\ esos \\ gigantes verdes egoístas \\ mandados por el afuerino invasor \\ se la tragaron \\ ellos se hacen más fuertes \\ carcomiéndole el espíritu \\ a los habitantes ancestrales (Falabella, Huinao y Miranda 82).
}

El poema "Deshidratándole la Vida" actualiza un sistema performático que comienza con una afirmación negativa: "Ya no corre/ más agua por estas tierras". La voz autorial de la zomo weycafe se constituye denunciando una pérdida, activando memorias de distintos tiempos generacionales: el de un mundo de adultos y el de un mundo infantil. Recurre a la literatura infantil para significar una precariedad existencial y política, de desigualdad de condiciones, donde los "gigantes verdes egoístas" se "hacen más fuertes" y son mandados por un malvado "afuerino invasor". Karla Guaquin escribe en la isla de Chiloé (su hogar), donde están realizando un proceso de recuperación de territorio y de la cultura mapuche. Denuncia el actuar de los invasores, las empresas transnacionales de la industria maderera, que plantan árboles foráneos que absorben toda el agua.

El lenguaje poético es lacónico y simple. La voz autorial enuncia un presente cruel basado en la falta y la agresión, de vida precaria. El poema va formando una cadena metonímica, propia de la tradición oral. Activa sucesivos imaginarios, que van intensificando la posición de vulnerabilidad de la voz: agua - ecología, gigantes verdes egoístas - infancia, afuerinos campo, invasores - colonia/ imperio, ellos se hacen más fuertes - desigualdad,

Beca Nacional de Escritores (2006 y 2008), y en 2012 el prestigioso Premio Municipal de Santiago, misma distinción que ganó Gabriela Mistral en 1914. 
carcomiéndoles el espíritu - espiritualidad y ética, habitantes ancestrales mapuche. Como sistema performático, el poema funciona como un conjunto de cajas chinas, donde una caja-imaginario está contenida dentro de otra, y así sucesivamente. Leemos en la obra de Guaquin tretas del débil en su poesía, donde, en las cadenas de intensidades, la sensación de precariedad se ve profundizada por la mirada infantil: los gigantes verdes ya se tragaron el agua, elemento fundamental para la vida. ¿Queda vida? El uso de los gerundios "deshidratándole" y "carcomiéndole" deja entrever un hilito de esperanza.

En el ensayo "Performatividad, precariedad y políticas sexuales", Judith Butler profundiza en el carácter performativo del proceso de la constitución de la subjetividad, señalando que:

La performatividad es un proceso que implica la configuración de nuestra actuación en maneras que no siempre comprendemos del todo, y actuando en formas políticamente consecuentes. La performatividad tiene completamente que ver con "quién" puede ser producido como un sujeto reconocible, un sujeto que está viviendo, cuya vida vale la pena proteger y cuya vida, cuando se pierde, vale la pena añorar. La vida precaria caracteriza a aquellas vidas que no están cualificadas como reconocibles, legibles o dignas de despertar sentimiento. Y, de esta forma, la precariedad es la rúbrica que une a las mujeres, los queers, los transexuales, los pobres y las personas sin Estado (335).

La precariedad de la vida está dada por un Estado violento, que niega la posibilidad de que ciertas vidas sean "reconocibles, legibles o dignas de despertar sentimiento" (ibid.). Esto es, un Estado cuyo sistema excluye ciertas vidas: la de "las mujeres, los queers, los transexuales, los pobres y las personas sin Estado" (ibid.). Se trata de un Estado-nación que ejerce prácticas violentas de "borrar" a sujetos, rindiéndolos inintelegibles, como los "habitantes ancestrales" del poema de Guaquin, cuyo espíritu está siendo carcomido. El poema "Deshidratándole la Vida" a la vez denuncia y resiste el poder violento que agresivamente produce vidas precarias, ilegibles e irreconocibles.

Si revisamos la historia podemos constatar que el Estado de Chile ha sostenido una larga relación de conflicto con el pueblo mapuche, el mismo pueblo que Alonso de Ercilla canta en el poema épico La Araucana (1569) y cuyo imaginario ha operado por siglos como inspiración para el Imperio 
español y la República chilena. En La Araucana, que es un modelo para la escritura heroica de su época, el pueblo mapuche -o "araucanos", como se les llamaba hasta mediados del siglo XX-son reconocidos y celebrados como los grandes héroes nobles de los territorios recién "descubiertos". Escrito en Madrid y autorizado por la Corona, este es el primer libro que se refiere a Chile y es donde se acuña la imagen de este territorio como desconocido y beligerante, y del pueblo mapuche como heroico.

Diversos estudios señalan que el discurso de Ercilla fue estratégico para explicar y legitimar el dominio del Imperio sobre los territorios de la Abya Yala (Biotti 218). Se trataría de un gesto discursivo para avalar la usurpación de tierras en la colonia, del cual el imaginario criollo es heredero. Es en el imaginario de La Araucana donde se basa el discurso patriótico de la Independencia. Un ejemplo de ello es el hecho de que la logia de "los padres de la independencia" se denominaba Logia Lautaro.

Roberto Castillo Sandoval sostiene que el imaginario de La Araucana opera como base para lo que denomina un "desplazamiento onomástico", que tiene lugar en el discurso de la nación republicana:

El desplazamiento onomástico que permite bautizar al chileno patriota con el nombre del araucano heroico va acompañado de una transferencia análoga entre la República de Chile y el territorio de Arauco: así como el nombre de Caupolicán es definitivamente chilenizado, la Araucanía es apropiada y sustituida por Chile. Arauco y Chile son los elementos territoriales de la tensa ecuación ideológica que se remonta a Ercilla, la que puede ser resuelta al lograrse por fin la posesión efectiva de la Araucanía y la capitulación de sus rebeldes habitantes (231-232).

El autor plantea que el discurso fundacional de la nueva República, al "chilenizar" los nombres mapuche, estaría realizando una operación discursiva mediante la cual se legitima la guerra de Arauco y la posterior apropiación de los territorios mapuche. Castillo Sandoval profundiza su argumento señalando que el discurso histórico sobre la guerra de Arauco cumplió y sigue cumpliendo hoy en día con "borrar a la Araucanía": "La República de Chile, en efecto, borra a la Araucanía con una conquista militar cuyos emblemas - procedentes a todas luces del mito ercilianohacen posible que la ocupación se represente como si fuera de verdad una recuperación" (232). 
Con el tiempo, el discurso patriótico se normaliza y naturaliza, invisibilizando la violencia fundacional de la borradura de la Araucanía y el rechazo a todo aquello que afirme la identidad mapuche. Con ello, el ser mapuche se convierte en el enemigo interno por excelencia. El ser mapuche pasa a ser el "otro constitutivo" de la nación chilena, lo abyecto que debe ser excluido de lo visible, borrado para garantizar el orden, la paz y la prosperidad. Pero, ¿cuáles son las implicancias del desplazamiento onomástico que termina volviendo abyecto el ser mapuche para el discurso patriótico nacional? Para Judith Butler, lo "abyecto"

designa aquí precisamente aquellas zonas "invivibles", "inhabitables" de la vida social que, sin embargo, están densamente pobladas por quienes no gozan de la jerarquía de los sujetos, pero cuya condición de vivir bajo el signo de lo "invivible" es necesaria para circunscribir la esfera de los sujetos. Esta zona de inhabitabilidad constituirá el límite que defina el terreno del sujeto; constituirá ese sitio de identificaciones temidas contra las cuales $-\mathrm{y}$ en virtud de las cuales- el terreno del sujeto circunscribirá su propia pretensión a la autonomía y a la vida. En este sentido, pues, el sujeto se constituye a través de la fuerza de la exclusión y la abyección, una fuerza que produce un exterior constitutivo del sujeto, un exterior abyecto que, después de todo, es "interior" al sujeto como su propio repudio fundacional (Cuerpos 20).

En este sentido, podemos ver cómo el "ser mapuche" se constituye para la identidad nacional en lo "invivible", en el límite del "ser chileno", esto es, en un límite temido que, si se traspasa, significa la destrucción de "su propia pretensión a la autonomía y a la vida".

Es en este escenario social y político que Karla Guaquin crea su obra poética, lo hace desde un lugar que enfrenta un Estado-nación hostil que rinde subjetividades inintelegibles, borrándolas. Se trata de un lugar con distancias asimétricas donde reina la discordia. En "Deshidratándole la Vida", denuncia el impacto de la precarización de esta ideología sobre la vida, el agua (fuente de vida) y los habitantes ancestrales. Su escritura se resiste a la invisibilización y al exterminio nombrando y enunciando desde la vulnerabilidad de una voz, no solo a nivel existencial, sino también político. Encarna la resistencia que vuelve visible y reconocible la vida precaria producto de la desigualdad desde una posición de vulnerabilidad, acto que pone en entredicho el discurso patriótico de la nación de Chile (que justamente se basa en la exclusión de 
dicha vida, tornándola precaria). Es más, el sistema performático del poema de Guaquin tiene como efecto la conformación de una subjetividad que, desde una constitución vulnerable, se resiste al poder a la vez que establece sus condiciones para existir y ser visible: la poesía.

A partir de ello, propongo que el discurso poético mapuche opera como un trawun (encuentro o asamblea), esto es, una forma de asamblea política cuya genealogía no podemos trazar ni en un mapa urbano ni en una ciudad determinada, sino en representaciones literarias, actividades y escritos poéticos, así como en las materialidades etéreas de lo digital ${ }^{11}$. ¿Qué dispositivos performáticos operan en resistencia y subversión para con el paradigma histórico que ha naturalizado al pueblo mapuche como enemigo interno de la nación?

Históricamente, la poesía ha sido uno de los medios más destacados para articular la resistencia política y cultural de los mapuche frente a la represión. Esto es comprensible dada la cercanía de la poesía con la tradición oral y su flexibilidad para dar voz a imaginarios diversos, que la convierten en un género paradigmático para la unión de voces entre generaciones. Respecto a los inicios precisos de la poesía mapuche moderna, las opiniones están divididas. Iván Carrasco lo fecha en 1966, cuando Sebastián Queupul Quintremil publicó sus Poemas mapuches en castellano, un pequeño volumen que tiene cuatro poemas bilingües en mapudungún y castellano (723). Sin embargo, el reconocido poeta mapuche Elicura Chihuailaf sitúa tal inicio mucho antes, en la década de 1930, cuando los poemas mapuche aparecían con frecuencia en los periódicos La Voz de Arauco (Temuco), El Heraldo y El Frente Araucano (ambos de Santiago). El año 1939 destaca por la publicación del Canarero Araucano de Anselmo Quilaqueo, identificado por Chihuailaf como "un hito editorial" y "quizás la primera obra creada y también publicada y difundida por iniciativa de nuestros hermanos" ("Poesía mapuche" 38)

Como consecuencia de la imposición de la censura, el terror y el exilio por parte de la dictadura, se restringió la circulación de personas y material publicado. Escritores organizados localmente, ya sea en Chile o en el exilio,

11 La vida político-cultural y espiritual mapuche tiene una rica existencia en los medios digitales, donde la distancia territorial, producto de las múltiples diásporas, se ve salvada a través del uso intensivo de las nuevas tecnologías (blogs, páginas web, portales y aplicaciones, YouTube, Facebook e Instagram, sobre todo).

12 Cabe destacar que todas las referencias anteriores a 1980 son siempre de poetas mapuche masculinos. 
formaron talleres literarios que inspiraron nuevas formas de expresión, incluida la publicación de boletines. Las escritoras mapuche participaron en estos espacios y dinámicas desde el principio y también formaron sus propias organizaciones (Mora Curriao y Moraga 30), donde los talleres literarios fueron un espacio clave para la producción y difusión de la creación poética mapuche durante este periodo (Mora Curriao y Moraga 126). Además, se publicaron boletines políticos y culturales en el exterior, trípticos, cuadernillos y revistas, pequeñas y esporádicas, que incluyeron poesía mapuche. Algunas de estas plataformas de circulación internacional fueron el Boletín Mapuche en Inglaterra, entre 1978 y 1981, donde se publicaron relatos y poemas en mapudungun, y Huerrquen, publicado por la poeta Rayen A Kvyeh en Bélgica, entre 1982 y 1984. Huerrquen se convirtió en el boletín oficial del Comité Exterior Mapuche. A través de este medio, María Teresa Panchillo publicó el poema "Calibre 2.568" a mediados de la década de 1980, destacando la importancia de la poesía en los años de la dictadura como estrategia política y como espacio para la reconstrucción de la historia.

Recién con el "retorno a la democracia", las poetas mapuche comenzaron a ser reconocidas como autoridades e iguales, no solo cultural, sino también institucionalmente (Mora Curriao y Moraga 8). Ciertamente, las circunstancias que hicieron posible esta "emergencia" están relacionadas con los roles sociales y políticos que jugaron las mujeres en la lucha por el retorno de la democracia y su empoderamiento a través de los movimientos solidarios y feministas, tanto locales como transnacionales. Sin duda, también están relacionadas con el papel social tradicional que desempeñan las mujeres mapuche para mantener viva la tradición oral y preservar la memoria de su pueblo. Entre los importantes actos de reconocimiento institucional de este periodo se encuentran que Graciela Huinao fue elegida miembro permanente de la Academia Chilena de la Lengua y que Roxana Miranda Rupailaf ganara prestigiosos premios de poesía nacional e internacional ${ }^{13}$.

En efecto, el fin de la dictadura cívico-militar, en 1990, abrió la esfera pública chilena a una época de globalización intensificada, colmada de deseo de integrar identidades infrarrepresentadas durante mucho tiempo. Desde entonces, las y los mapuche han podido mantener su propia situación y su voz en el centro del escenario político. Junto a otros sujetos sociales,

13 Ambas poetas son parte del proyecto "Encuentro con mujeres mapuche". Hilando en la memoria. 
como las mujeres y las comunidades LGBTIQ+, han luchado por su derecho democrático a "aparecer" como sujetos políticos y culturales autónomos. Sin embargo, sus prácticas políticas y culturales, y sus justos reclamos, tendieron a romper el clima de celebración del inicio de la transición a la democracia -el lema de campaña del plebiscito contra Pinochet fue "La alegría ya viene"-. Las voces mapuche siguen siendo muy críticas con el nuevo estilo de democracia neoliberal de Chile. Su discurso socava las lógicas establecidas de dominación y colonización, subrayando la matriz violenta que todavía está en juego (Tricot 182).

Hoy en día, las tradiciones orales, los recuerdos de la violencia y los asesinatos de los supervivientes de la primera generación de los traslados a las Reservas siguen vivos. Ejemplos inquietantes de humillación, violación $\mathrm{y}$ asesinato de mapuche se entrelazan a través de relatos de violaciones de derechos humanos de seres queridos durante la dictadura. Ante esto, la proximidad de la tradición oral y la poesía ha producido un rico y estético encuentro de voces de diferentes generaciones, que permite una multiplicidad de memorias políticas y culturales. En palabras de Graciela Huinao, autora y coeditora de Hilando en la memoria:

Como nuestras abuelas cuando tejían en su tapiz las ausencias, el silencio de la tristeza y las alegrías, hoy cavilamos nuestra vida y la de nuestros antepasados para seguir tejiendo la memoria con la esperanza de que el hilo de la palabra hilada nunca se rompa. Nos encontramos anudando con un mismo hilo literario la tradición oral, la escritura y la memoria. No ha sido fácil montar este telar literario con nuestros propios olores, gustos y códigos (Huinao et al. contraportada).

La omnipresente matriz de violencia descrita anteriormente produce recuerdos que activan las experiencias traumáticas tanto de mapuche como de chilenos. Un complejo tapiz de postmemoria se teje en la resistencia cultural mapuche, produciendo subjetividades y sociabilidades vulnerables y permeables. "Postmemoria", argumenta Marianne Hirsch, "describe la relación que la 'generación siguiente' tiene con el trauma personal, colectivo y cultural de aquellos que vinieron antes, con experiencias que 'recuerdan' solo por medio de historias, imágenes y comportamientos entre los que crecieron" (106). Es importante destacar que la postmemoria, como señala Hirsch, mantiene "vivos" eventos y vivencias del pasado, creando una "oscilación incómoda entre la continuidad y la ruptura" (ibid.). 
La escritura de las mujeres mapuche muestra que las vulnerabilidades derivadas de la memoria y postmemoria de siglos de opresión, discriminación y no reconocimiento son capaces de subvertir la misma legalidad performática que las violenta y busca borrar. Siguiendo a Butler, la posición de vulnerabilidad tiene el potencial subversivo de funcionar como una forma de resistencia. Entonces podemos ver cómo la poesía puede convertirse en un dispositivo transformador, un sistema performático que torna la vulnerabilidad en agencia infundida de futuro. Como veremos a continuación, la poesía de las autoras mapuche contiene la fuerza performativa capaz de desarticular el discurso nacional bélico y exterminador, desatando nuevas formas de deseo de estar en el mundo de forma plena, legítima y digna.

El activismo que comenzó con la urgencia de romper y transformar el statu quo de la esfera pública contemporánea, afirmando "para que nunca más" ("para que nunca vuelva a suceder"), ha evolucionado para plantear nuevas preguntas: ¿Cómo aflora la resistencia cultural política mapuche en medio de los recuerdos afectivos autoritarios que se han transmitido a través de muchas generaciones? ¿Cómo se relacionan estas prácticas con los movimientos globales y remodelan las identidades nacionales en el futuro?

En i...Escucha, Winka...! (2006), estudio histórico en el que los autores ponen al descubierto las tensiones entre la sociedad mapuche y la winka (blanca) se afirma:

Quizás podríamos quedarnos con esta visión [dicotomizada] y ponerte en la posición del enemigo. Sin embargo, estamos seguros que madurará en ellos (ustedes) una posición que no es ni paternal ni mesiánica hacia nosotros, y que romperá sus máscaras Winka y reiniciará el disco duro grabado en usted, el criollo (élites coloniales españolas y europeas), la única verdad winka. Cuando se les considera no solo masas de votantes o consumidores, sino también sujetos diferenciados de una nación plurinacional, la categoría winka se volverá obsoleta. También aspiramos a soltar nuestra condena absoluta hacia ustedes por el papel que jugó su Estado en nuestro dominio y empobrecimiento. Al menos, somos políticamente conscientes de que pensar el futuro $[\ldots]$ nos lleva a aceptar tu presencia y asumir la posibilidad de un mutuo entendimiento profundo y respetuoso (13-14).

En este discurso se reconoce la trampa de la visión dicotómica excluyente del discurso winka, donde solo existen dos posiciones mutuamente excluyentes: amigo o enemigo. Este reconocimiento sirve como base para plantear otra 
forma de estar en el mundo, no solo como individuos, sino también como comunidades nacionales que pueden convivir en un Estado plurinacional donde existe "la posibilidad de un mutuo entendimiento profundo y respetuoso".

\section{LA ESTÉTICA DE LA RESISTENCIA}

Al integrar la tradición oral con las experiencias contemporáneas, las y los poetas mapuche conectan nuevos significados con formas antiguas. El poeta Elicura Chihuailaf, ganador del Premio Nacional de Literatura en 2020, se refiere a los textos poéticos mapuche como "oralitura" ("Elicura" 51). La autora y crítica de Hilando en la memoria, Maribel Mora Curriao, explica que

toda lectura de poesía realizada por el autor, frente a un público, es una performance. Ello debido a que el sujeto que lee sus poemas, adopta una actitud coherente con su discurso (transgresor, melancólico, místico, etc.), para comunicar de mejor manera. [Esto] implicaría una voluntad artística, [...] de actuar una situación para llamar la atención de un público determinado (Huinao et al. 119) ${ }^{14}$.

La ejecución del discurso poético tiene la capacidad de exceder la página textual y difundir energía creativa más allá de sí misma, creando las condiciones para el surgimiento de nuevos mundos de energía transformadora.

El trabajo de María Huenuñir ejemplifica este patrón. Huenuñir, hablante nativa de mapudungun, canta y escribe textos bilingües. Ella emigró de Cayumapu Alto a Santiago a principios de la década de 1980, debido a la crisis económica de aquellos años. Su poesía habla de sus recuerdos de su tierra natal y de la tradición oral que recibió de sus mayores, creando vínculos entre culturas rurales y urbanas y entre generaciones. Actualmente, además de actuar para un público variado, Huenuñir trabaja como Educadora Tradicional de niños y niñas en edad preescolar para el Ministerio de Educación. Su poema "Meli" ("Cuatro") es parte del plan de estudios que imparte:

14 Para más lecturas sobre este tema, ver los trabajos de Ángel Rama, Antonio Cornejo Polar, Martin Lienhard, Mabel Moraña y Julio Ramos. 


\author{
"Meli" (Cuatro) \\ Fueron cuatro cauces \\ que me dieron vida \\ cuatro amaneceres \\ formaron mi día. \\ De cuatro sangres rotas \\ mi cuerpo se formó \\ de cuatro venas nuevas \\ mi corazón latió. \\ Cuatro puntos profundos \\ me hicieron girar \\ y en el centro del mundo \\ vine a rebrotar. \\ Desde cuatro mares \\ se formó mi río \\ desde cuatro montes \\ nace mi respiro. \\ Tengo a cuatro ancianos \\ formando una flor \\ su centro son mis ojos \\ abrigados de sol. \\ Sus manos son mi escudo \\ afirmando el valor \\ en un sitio nuevo \\ signos de mi honor. \\ Son mis cuatro abuelos \\ marcando mis senderos \\ protegiendo mi destino \\ de todo el modernismo (29).
}

Desde el comienzo, el poema "Meli" encarna una poética de la resistencia: lleva su nombre en mapudungun, lengua que desde hace más de un siglo y medio el Estado chileno ha buscado prohibir y borrar (Soto 64). Canta sobre el número cuatro, que en la cosmología mapuche es sagrado. En "Meli", la voz poética va enumerando de forma cíclica -como los cuatro ciclos de la naturaleza- los fundamentos de la existencia de la voz poética, basada en la repetición del número cuatro, tanto a nivel simbólico como material. 
Para empezar, se forma una cadena de palabras que hablan de su ser natural, genealógico y ancestral: cauces, amaneceres, sangres, venas, puntos, centro del mundo, ríos, mares, montes, ancianos, flores, manos, abuelos. Al igual que en el poema anterior, el sistema performático de "Meli" contiende una oralidad muy activa, que se hace presente en la cadena de significantes y sus imaginarios. Estos se articulan de forma aditiva e inclusiva, consciente de su carácter plural, movilizando la energía performática del discurso. También ocurre una intensificación de dicha pluralidad a nivel metonímico, a través del verso octosílabo (factor de dos y cuatro), la rima asonante regular y la estructura formulaica y repetitiva.

La intensificación no solo existe a nivel sintagmático, sino también a nivel de paradigma, a través del concepto del número cuatro, que simboliza la integralidad existencial, natural y cosmológica de la espiritualidad mapuche. En efecto, el número cuatro se repite en diversos elementos paradigmáticos del poema: el tipo de verso (octosílabo, siendo ocho el factor de dos y cuatro), el equilibrio y la aparente integralidad que busca encarnar.

Como sistema performático, "Meli" está impregnado del küme felen o küme mogen (la buena vida, el vivir bien), que es compartida por otros pueblos indígenas andinos, como el quechua y el aymara. Este concepto expresa el equilibrio, la integralidad y la complementariedad que sustentan el universo donde se da el bien común. Como dice Juan Paulo Huirimilla, küme felen busca lograr un "equilibrio entre piwke (corazón), rakiduam (pensamiento), kalül (cuerpo) y püyü (espíritu)" (párr. 3). Y a menudo se articula con otro concepto, el de itrofill mogen, que significa respeto por todos los seres vivos y la biodiversidad: "totalidad sin exclusión" o "la integridad sin fragmentación de la vida, de todo lo viviente" (Chihuailaf, "La importancia" 01:55-02:05).

Aparentemente, el lenguaje del poema fluye armoniosamente, solo hay un atisbo de precariedad, un rastro que apunta a que algo más está pasando: la "sangre" de la que está hecha está "rota". Sin embargo, hacia el final del poema, la palabra "modernismo" se articula con el sintagma "sangre rota", rompiendo la armonía y amplificando los sentidos que parecían ser estables, repetitivos y cíclicos. El efecto del sistema performático de la escritura poética incluye una vulnerabilidad muy específica: la ruptura de sangre que implica la modernidad. María Huenuñir Antihuala migró a Santiago desde las montañas de Panguipulli, es una mujer mapuche rural que habita la metrópoli en la que debe luchar día a día contra lo que ella denomina "modernidad". 
A nivel actancial, la integración de la posición vulnerable de la voz poética constituye este poema en un espacio doblemente resistente, una treta del débil cuya performatividad le otorga un poder de agencia, resistencia y transformación: funciona como un talismán que transforma la precariedad de la sangre rota y la modernidad. Realiza una activación de küme felen e itrofill mogen, no solo reactivando memoria y conocimiento ancestrales, sino creando y comunicando nuevos conocimientos innovadores, capaces de movilizar a las audiencias en función del equilibrio cosmogónico de la cultura mapuche. Anima a su audiencia con nueva vida, aunque precarizada, transformando su vulnerabilidad en resiliencia.

"Meli" es uno de los poemas más populares de María Huenuñir. En las representaciones, su canto es melodioso hasta que se rompe al final con la extrañeza de la palabra "modernismo". En este poema, la performance y la oralidad se refuerzan para construir un escenario existencial, espiritual y político impregnado de la vitalidad y del aquí y ahora, un lugar específico que la autora se da a sí misma y a sus audiencias. En efecto, estamos ante un lugar donde las subjetividades colectivas pueden emerger y formar comunidad en diálogo con el mundo ancestral y contemporáneo. En un contexto de exclusión histórica de las voces mapuche de la esfera pública chilena, representaciones poéticas como la suya constituyen un arma de resistencia a la criminalización, dominación y colonización que ha promovido históricamente la nación chilena ${ }^{15}$.

Algo distinto ocurre en el poema "Paseo Ahumada" de Faumelisa Manquepillan, cuyo sistema performático activa dispositivos de resistencia y transformación a través de la lectura y escritura de cartas a sus seres queridos:

15 María Huenuñir, como la mayoría de las mujeres mapuche mayores en el Proyecto, ha estado interpretando su poesía constantemente desde principios del año 2000. Mujeres como Huenuñir son consideradas líderes comunitarias y, como tales, sus voces son parte fundamental de una práctica más amplia que se manifiesta durante el trawun o reuniones. Estos ocurren constantemente en todo el país como parte de celebraciones rituales, ferias de campo, encuentros políticos o culturales. Durante la semana Huenuñir trabaja como educadora tradicional. Ha habido una gran migración de las comunidades rurales a la ciudad y hoy más de la mitad de la población mapuche en Chile vive en Santiago, principalmente en las comunas exteriores como Cerro Navia, La Pintana, El Bosque, Lo Prado, Peñalolén y Pudahuel (donde vive María Huenuñir). En su papel de educadora, comparte su poesía con los niños en edad preescolar. Actualmente, muchas de las mujeres mapuche del Proyecto Hilando en la Memoria trabajan como educadoras. Como tal, la representación de su poesía tiene lugar tanto en su práctica laboral diaria como en su práctica tradicional mapuche. 
"Paseo Ahumada" es la voz poética que surge desde esa experiencia cuando Faumelisa Manquepillan debe migrar a la ciudad de Santiago a inicios de los años 80 , dejando su tierra natal para trabajar como "nana puertas adentro", producto de una crisis económica que impactó con fuerza en las comunidades mapuche y que generó experiencias de pobreza y hambre, presionando a parte de su población [...] a lo que se ha llamado "exilio interno" (Peralta 6).

El poema escenifica la voz de "nana" de un barrio de clase alta de Santiago, que se desplaza al centro de la ciudad en su día libre:

"Paseo Ahumada"

Era una mujer que cada semana iba del trabajo al Paseo Ahumada Buscaba un sombrero entre las miradas

Para cobijarse porque se asustaba.

En el Barrio Alto

se le encontraba, con un delantal vestida de nana, con un niño rubio, que a veces besaba.

En el Paseo Ahumada, siempre cabizbaja, su mirada lejos, se le observaba.

Un ruego en la boca siempre entonaba, en el Paseo Ahumada.

Atenta al cartero, siempre esperaba, a que alguna carta se le entregara.

¿No vendrá del Sur?

ella preguntaba, en el Paseo Ahumada.

Era una mujer, que delantal llevaba, soñando su tierra, siempre esperanzada, queriendo volver con su familia amada, 
en el Paseo Ahumada.

Esta capital

(a veces contaba

en las largas cartas

que siempre enviaba)

entre ruido y humo, me tiene atrapada.

¡Ayúdenme a salir, del Paseo Ahumada! (Manquepillan 42-43).

La precariedad se vislumbra en el tono impersonal del poema, la falta de apego a su entorno y al "niño rubio" que debe cuidar. Su alienación llega a través de la rima monótona de los versos en español, que terminan en "-aba", imitando el sonido de un personaje idiotizado.

La voz de la enunciación subraya la búsqueda de reconocimiento ante una sociedad que no la acoge. Su escenario es hostil. Las y los transeúntes no le devuelven la mirada, dejándola sola a la intemperie social. A su vez, el lugar donde está, la capital, "entre ruido y humo me tiene atrapada":

\author{
Esta capital \\ (a veces contaba \\ en las largas cartas \\ que siempre enviaba) \\ entre ruido y humo, me tiene atrapada. \\ ¡Ayúdenme a salir, del Paseo Ahumada! (Manquepillan 43).
}

Vemos cómo, en el poema "Paseo Ahumada", la voz crea un espacio propio de protección y fuga del Paseo Ahumada y la ciudad que la aliena y retiene, un espacio epistolar investido por su deseo, una treta del débil otorgada por un lugar que logra reclamar como propio. En efecto, es solo cuando escribe cartas a sus seres queridos describiendo su vida en Santiago que puede materializar su necesidad de escapar. La posibilidad de vincularse con el deseo propio se abre en la escritura de cartas a su familia y comunidad añorada. Solo partir de la creación de este lugar específico logra vincularse con su hogar y constituir plenamente la subjetividad del poema, que clama auxilio: “¡Ayúdenme a salir, del Paseo Ahumada!”.

En Hilando en la memoria, Faumelisa Manquepillan explica su decisión consciente de regresar a su tierra natal: 
En el útero de Pukiñe (Los primeros), a quince kilómetros de Lanco: Vivo. [...] Elegí vivir en el campo, a pesar de todas las "faltas" de desarrollo, aquí estoy como un árbol más. Un tiempo viví fuera de mi comunidad, fue muy difícil mi estadía en Santiago y cuando volví a la capital tuve que reconciliarme con la ciudad (Huinao et al. 129).

En contraste con la asertividad de "Meli", "Paseo Ahumada" exhibe una marcada vulnerabilidad. Es en la recepción del poema como acto de transferencia donde se encarna el espíritu del küme felen. De hecho, este poema se ha convertido en un texto icónico sobre la alienación que sufren en Santiago no solo las mujeres mapuche, sino todas las mujeres que tienen que soportar las dificultades de la migración del campo a la ciudad para convertirse en nanas de hogares de clase alta y/o winka.

María Lugones, crítica feminista decolonial, menciona una de las condiciones más conmovedoras que surgen de este campo: la cultura de la "indiferencia" que ha sostenido la dominación colonial y ha apoyado la dominación de género. Afirma que "esta indiferencia es insidiosa porque impone barreras impasables en nuestras luchas como mujeres de color por nuestra propia integridad, autodeterminación, la médula misma de las luchas por la liberación de nuestras comunidades" (76). Se puede leer "Paseo Ahumada" como puesta en escena de la cultura de la "indiferencia" que denuncia Lugones, esa indolencia que debe existir para sostener la dominación colonial basada en la raza, la clase y el género.

El poema también contrasta marcadamente con la voz neovanguardista exquisitamente irónica del poeta Enrique Lihn, cuya epopeya El Paseo Ahumada (1983) denuncia la precariedad de los medios de vida de los habitantes de este emblemático paseo peatonal de Santiago. Escrito en dictadura, durante la crisis económica de los años ochenta, su voz poética "representa" el mundo de los "sin voz" del paseo a través del retrato del "Pingüino". Lihn se compara irónicamente con el Canto General de Pablo Neruda:

\section{Canto General}

Mi Canto particular (que te interprete, pingüino), producto de la recesión y de otras restricciones

Soy un cantante limitado, un minusválido de la canción

Canto General al Paseo Ahumada

vuestro monumento viviente (Habrá otros, habrá otros: la inmortalidad no es impaciente) 
Canto General de esta toma parcial de la naturaleza muriente de Santiago

y de 1 os productos que producen a los hombres made in Taiwan ellos se desviven

enfervorizados por venderlos

a cien pesos la unidad (9-10).

Faumelisa Manquepillan pone en cortocircuito la voz eléctrica y voraz de Lihn - quien invoca la obra magna del "padre de la poesía chilena", Pablo Neruda- al traer al escenario la voz fina e impersonal de una tercera persona al borde del colapso, casi inexistente, apenas sobreviviente, atrapado entre el "ruido y el humo" de la gran ciudad. El discurso de Manquepillan moviliza otras memorias muy distintas al canon cultural tradicional chileno. No es una voz monumental que pretende hablar por los demás o gesticular a la totalidad; en cambio, la voz vive a través de su vulnerabilidad al reclamar como último recurso el recuerdo persistente del hogar.

La promulgación de esta posición de vulnerabilidad produce nuevos tipos de relaciones y sociabilidades que resisten, critican y transforman los imaginarios canónicos chilenos, como los representados por Lihn y Neruda. Manteniendo esta posición, el sujeto vulnerable moviliza recuerdos colectivos vividos y encarnados para imaginar nuevas formas de ser en el mundo. Como en "Meli", el sujeto de "Paseo Ahumada" encuentra consuelo y fuerza en el contacto con su hogar ancestral, que simboliza como un útero, reforzando la herencia matrilineal de su familia y su propio deseo femenino.

\section{CONCLUSIÓN}

A lo largo de este ensayo he buscado indagar en cómo las obras poéticas de Karla Guaquin, María Huenuñir y Faumelisa Manquepillan han creado y puesto en circulación sistemas performáticos resistentes, capaces de subvertir el discurso nacional patriótico chileno que, desde su instauración, se ha construido en oposición del "ser mapuche", convirtiéndolo en un exterior constitutivo, legitimando así la usurpación de tierras. Tal como lo hace Sor Juana Inés de la Cruz en la "Respuesta a Sor Filotea de la Cruz" -donde enfrenta la embestida del obispo de Puebla que la amenaza con la Inquisición-, las autoras logran fundar mediante su escritura poética un espacio a la vez propio y colectivo, marcado por las condiciones específicas de su creación 
de abyección histórica y asimétrica. Su tejido de voces colectivas entra a la esfera pública nacional y global tornando la precariedad de la vida en un lugar de encuentros comunitarios donde trabajar la memoria y la postmemoria del trauma de la violencia fundadora de los estados, en nuestro caso de la República de Chile. De esta forma, crean una nueva forma de asamblea pública, un trawun cuyo ethos está basado en la práctica de los principios del küme felen y el itrofill mogen. Así, en palabras de Paulo Huirimilla, la poesía es donde existen las condiciones para lograr un "equilibrio entre piwke (corazón), rakiduam (pensamiento), kalül (cuerpo) y püyü (espíritu)" (párr. 3).

En efecto, el lenguaje de Karla Guaquin, María Huenuñir Antihuala y Faumelisa Manquepillan Calfuleo, junto al coro de voces de sus lamgen (hermanas) autoras, actualiza dispositivos movilizadores de memoria comunitaria y transgeneracional. En el escenario actancial de su poesía, la oralidad visibiliza la vulnerabilidad, vitalizándola e infundiéndole newen (energía) para transformarla en agencia. De este modo, la precariedad se transforma en un lugar desde donde resistir, crear y comunicar nuevos conocimientos emancipadores que no se limitan a sus comunidades, sino que a todes les que participemos del trawun poético, una comunidad que incluye tanto a la población mapuche como a otros habitantes del territorio que hoy llamamos Chile.

El trabajo transformador que hemos evidenciado en la poesía de mujeres mapuche significa un valioso aporte para la sociedad chilena, al permitirnos habitar la vulnerabilidad y transformarla en un lugar lleno de potencial de futuro y de agencia. Esta escritura está preñada de un conocimiento nuevo, donde se vinculan lo ancestral y lo contemporáneo para las generaciones que vienen. Pienso que, como sociedad, las, les y los chilenos podemos identificarnos con nuestra propia vulnerabilidad de una forma productiva. Esta escritura funciona como tretas del débil, al decir de Ludmer, cuyo potencial de agencia, creación y transformación nos permite tomar contacto con nuestra propia vulnerabilidad y deseo, habitándolos para transformarlos en poder de agencia y posibilidades de futuro.

Esto es especialmente relevante hoy en Chile, cuando estamos en un escenario de revuelta social y de un proceso constituyente donde, por primera vez, una comisión democráticamente electa, paritaria y con participación de los pueblos indígenas del territorio, redactará la constitución del país. Esto es, cuando el pueblo a lo largo del territorio se está alzando en contra del poder hegemónico de las élites que durante siglos han perpetrado abusos, incluyendo crímenes contra la humanidad. En especial, es importante señalar 
que el daño infligido por el Estado chileno contra los pueblos sigue vigente en instituciones como el Servicio Nacional de Menores (SENAME) y el sistema judicial, que opera en base a leyes laberínticas que legalizan la usurpación de tierras y violaciones a los Derechos Humanos de los pueblos indígenas y la explotación de la población chilena, precarizada por la violencia política de la dictadura-cívico militar y el sistema neocolonial y neoliberal.

A su vez, cabe destacar la resistencia cultural y política mapuche que, a través de discursos poéticos que activan y transmutan aquella memoria que ha intentado ser reprimida, hacen frente a la expansiva y restrictiva identidad nacional chilena. En particular, la poesía de numerosas mujeres mapuche crea lugares que ocupan para legitimar formas de "estar en el mundo" históricamente excluidas. Las narrativas neocoloniales han construido una identidad nacional en base a la abyección del "ser mapuche", que opera como el "otro constitutivo" de la civilización, el "enemigo interno" a ser rechazado y dominado para garantizar el orden, la paz y la prosperidad. El levantamiento de sus voces poéticas y políticas ha permitido el surgimiento de nuevos deseos y conocimientos, incluido el respeto a sus Derechos Humanos. La circulación de nuevos lenguajes y formas de ver y ser, puede, en última instancia, impulsar las capacidades disidentes para cuestionar las normas y desarrollar nuevos imaginarios para la construcción de una sociedad postdictatorial.

El discurso poético de Karla Guaquin, María Huenuñir y Faumelisa Manquepillan es parte integral de la lucha política contra la violencia estatal y cultural en Chile, constituyendo así una forma de asamblea política, un trawun que las autoras ocupan para movilizar la memoria colectiva mapuche y transformar la vulnerabilidad en agencia. Las mujeres poetas mapuche también están deshaciendo y recreando un "nosotrxs" chilenxs.

\section{BIBLIOGRAFÍA}

Antilef, Elizabeth y Daisy Baltazar et Al. Viento a Favor: conociendo mis derechos previsionales. Santiago de Chile, Subsecretaría de Previsión Social, 2015.

Biotti Silva, Adriana. "Hacia una historia de la cultura escrita de Chile. Los devenires de La Araucana de Alonso de Ercilla. Santiago (1569- 1888)". Revista de Historia Social y de las Mentalidades 14, №2, 2010, pp. 217-233.

Butler, Judith. Cuerpos que importan. Barcelona, Editorial Paidós, 2001.

"Rethinking Vulnerability and Resistance". Vulnerability in Resistance. Butler, Judith Butler, Zeynep Gambetti et al. (eds.), Durham y Londres, Duke University Press, 2016. 
Butler, Judith. "Performatividad, precariedad y políticas sexuales". AIBR. Revista de Antropología Iberoamericana 4, º3, 2009, pp. 321-336.

Carmo, Marcia. “'Chile Despertó': Susana Hidalgo, la famosa actriz que tomó la imagen más icónica de las protestas". British Broadcasting Corporation (BBC). 30 de octubre de 2019 (web), consultado el 19 de noviembre de 2021, disponible en: https://www.bbc. com/mundo/noticias-america-latina-50239591

Carrasco M., Iván. "Literatura mapuche”. América Indígena 48, №4, 1988, pp. 95-728.

Castillo Sandoval, Roberto. “¿'Una misma cosa con la vuestra’?: Ercilla, Pedro de Oña

y la apropiación post-colonial de la patria araucana”. Revista iberoamericana LXI, N¹70171, 1995, pp. 231-247.

Chinuailaf, Elicura. "Poesía mapuche actual: Apuntes para el inicio de un necesario rescate". Liwen 2, 1990, pp. 36-40.

"Elicura Chihuailaf: En la oralitura habita una visión del mundo". Entrevista con Viviana del Campo. Revista Hispanoamericana de Poesía 3, 2000, pp. 49-59.

"La importancia del arte para la vida". Vimeo (web), 13 de mayo de 2014, consultado el 19 de noviembre de 2021, disponible en: https://vimeo.com/100415624

Falabella, Soledad, Graciela Huinao y Roxana Miranda Rupailaf (eds.). Hilando en la memoria. Epu rupa: 14 mujeres mapuche. Santiago de Chile, Cuarto Propio, 2009.

Hirsch, Marianne. “The Generation of Postmemory”. Poetics Today 29, N¹, 2008, pp. 103-128.

Huenuñir, María. "Meli". Viento a Favor. Juntas construiremos comunidades fuertes cuidadosas del futuro y del buen vivir. Elizabeth Antilef et al., Santiago, Subsecretaría de Desarrollo Social, 2014, p. 29.

Huinao, Graciela et al. (eds). Hilando en la memoria: Curriao, Huinao, Millapan, Manquepillan, Panchillo, Pinda, Rupailaf. Santiago, Cuarto Propio, 2006.

Huirimilla, JuAn Pablo. "El sentido de la muerte según relatos mapuche". Letras.s5 (web), 2004, consultado el 20 de noviembre de 2021, disponible en: http:/www.letras.mysite. com/jph090704.htm.

Jelin, Elizabeth. Los trabajos de la memoria. Madrid, Siglo XXI, 2002.

Linn, Enrique. El Paseo Ahumada. Santiago, Ediciones Minga, 1983.

Ludmer, Josefina. "Las tretas del débil”. La sartén por el mango. Patricia Elena González y Eliana Ortega (eds.), Río Piedras (Puerto Rico), Ediciones El Huracán, 1985, p. 47.

Lugones, María. “Colonialidad y género”. Tabula Rasa 9, 2008, pp. 73-101.

Manquepillan, Faumelisa. Zomo Pewma. Sueño de mujer. Temuco, Universidad de la Frontera, 2000.

Marimán Quemenado, Pablo, et Al. i...Escucha, Winka...! Cuatro ensayos de Historia

Nacional Mapuche y un epílogo sobre el futuro. Santiago, LOM, 2006.

Mora Curriao, Maribel y Fernanda Moraga García (comp.). Kümedungun / Kümewirin. Antología poética de mujeres mapuches (siglos XX-XXI). Santiago, LOM, 2011.

Portugal Mollinedo, Pedro y Carlos Macusaya Cruz. El indianismo katarista: un análisis crítico. La Paz, Bolivia, Fundación Friedrich Ebert, 2016. 
Prieto, Francisca. "Elicura Chihuailaf se adjudica el Premio Nacional de Literatura 2020". Emol (web), 1 de septiembre de 2020, consultado el 19 de noviembre de 2021, disponible en: https://www.emol.com/noticias/Espectaculos/2020/09/01/996672/Elicura-ChihuailafPremio-Literatura-2020.html

Soto, ElвA. “Mapuzungun y los procesos de colonización”, Universum 29, º1, 2014, pp. 57-83.

TAYLOR, Diana. “¿Qué son los estudios de Performance?” Entrevista con Barbara KirshenblattGimblett. Scalar (web), 2002, consultado el 19 de noviembre de 2021, disponible en: https://scalar.usc.edu/nehvectors/wips/diana-taylor-spanish

Tricot, Tiтo. Autonomía, el movimiento mapuche de resistencia. Santiago de Chile, Ceibo, 2011. Zumthor, PAul. "L'intertexte performanciel". L'intertextualité, intertexte, autotexte, intratexte. Andrew Oliver (ed.), Montreal, Les Éditions Trintexte, 1984. 